\title{
JOURNALS RECEIVED
}

Poznan Studies in the Philosophy of the Sciences and the Humanities, ed. by Leszek Nowak, B. R. Grüner Publishing Co., Amsterdam, Vol. I (1975) No. 1.

Teorie a Metoda, ed. by Karel Berka, Ustav Pro Filosofii a Sociologii CSAV, Vol. VII (1975), Nos. 1, 2; Vol. VI (1974), No. 1.

Sprache im technischen Zeitalter, ed. by Walter Höllerer und Norbert Miller, Heft 49 (1974), Verlag W. Kohlhammer, Stuttgart. 